\title{
LAS Curvas del Debilitado Camino DEMOCRÁTICO TUPINIQUIN: \\ Altibajos DE LA RECIENTE HISTORIA DE LA DEMOCRACIA EN BRASIL
}

\section{Cesar Santos Brunetto ${ }^{1}$}

Resumen: Los procesos políticos involucrados en la sociedad brasileña desde la constitución de la República en 1889 están marcados por crisis, inestabilidades discontinuidades, golpes y violaciones. Desde entonces, el período democrático representa no más que un tercio de todo el período republicano, entre idas y venidas de los 43 presidentes oficiales que el país tuvo desde 1889, menos de la mitad de ellos elegidos a través del voto directo. Contextualizar históricamente las etapas del desarrollo político en el país es condición para facilitar el análisis del período actual, es por eso, que a lo largo de este artículo se presentarán brevemente y en cinco apartados los momentos principales y hechos históricos de la República de Brasil. Se destacará el momento histórico conocido como la "Nueva República", el cual, es el período en el que se inicia la redemocratización de Brasil después de más de veinte años de dictadura militar, realizado a través de la elección indirecta a la presidencia del país en 1985, hasta la reciente elección presidencial de 2018.

Palabras clave: política brasileña; república; democracia, impeachment, movimientos sociales

Abstract: Since the establishment of the Brazilian Republic in 1889, the political processes that the country's society has gone through have been marked by crises, instabilities, discontinuities, coups and

\footnotetext{
${ }^{1}$ Máster en Sociología por la Universidad de Barcelona; cesarbrunetto@gmail.com
} 
violations. Since that moment, the country's democratic periods do not amount to more than one third of its whole republican phase, with the to-ings and fro-ings of its 43 official presidents, less than half of whom were elected by direct popular vote. Historical contextualization of the several stages of Brazil's political development is needed in order to facilitate the analysis of the present period. In this article, we shall briefly present, in five sections, the main milestones and historical facts of the Brazilian Republic. We shall highlight the historical moment known as the "New Republic", a period when, after over twenty years of military dictatorship, we witness the redemocratization of the country beginning with the indirect election of the country's president in 1985 and continuing up to the recent presidential election in 2018.

Keywords: Brazilian politics; republic; democracy; impeachment; social movements

Resum: Els processos polítics travessats per la societat brasilera des de la instauració de la República, l'any 1889, estan marcats per crisis, inestabilitats, discontinuïtats, cops i violacions. Des d'aleshores, el període democràtic representa només un terç de tot el període republicà, entre les anades i vingudes dels 43 presidents oficials que ha tingut el país des del 1889, menys de la meitat dels quals van ser escollits mitjançant el vot directe popular. Contextualitzar històricament les etapes del desenvolupament polític del país és condició per facilitar l'anàlisi del període actual. Al llarg d'aquest article es presentaran breument, en cinc apartats, els principals moments $i$ fets històrics del Brasil República. S’hi destacarà el moment històric conegut com la "Nova República", període en què s’inicia la redemocratització de Brasil, després de més de vint anys de dictadura militar, a partir de l'elecció indirecta a la presidència del país el 1985, fins a la recent elecció presidencial de 2018.

Paraules clau: política brasilera; república; democracia; impeachment, moviments socials 


\section{Capítulo 1: Constitución de La Primera República (República Vieja) 1889 - 1930}

a. La constitución de la República

La Proclamación de la República en Brasil tuvo lugar el 15 de noviembre de 1889, donde se instauró un nuevo sistema político que puso fin al régimen monárquico que había existido desde 1822, año de la independencia del país. La fundación de la República se realiza tras un golpe militar liderado por Marechal Deodoro da Fonseca que le transformará en el primer presidente del país a partir del mutuo apoyo entre la aristocracia rural, el ejército y una pequeña burguesía urbana e intelectual.

El movimiento republicano en Brasil, influenciado por los ideales positivistas de orden, conocimiento y progreso, venía difundiendo la propaganda republicana manifestándose a través de los diarios, clubes y partidos republicanos durante el siglo XIX, pero sin llegar a conseguir un apoyo mayoritario de la sociedad, ni a penetrar entre las clases dominantes. Sin embargo, es a partir de la última década del siglo en la que el movimiento se consolida gracias a la adhesión por parte de los militares descontentos que buscaban mayor participación política, principalmente tras la victoria de la guerra del Paraguay, y también por el apoyo de parte de la aristocracia de los granjeros de café (principalmente de São Paulo y Minas Gerais), movidos por su resentimiento con el fin de la esclavitud, ajenos al control del Estado, a pesar de ser la clase dominante en términos económicos. Además de la poderosa unión de militares y aristocracia rural, el movimiento se ve favorecido por un contexto en el que los conflictos existentes entre la Iglesia y el Emperador (por la interferencia del último en decisiones eclesiásticas) están también a la orden del día. Por último, la clase media urbana en ascenso ve favorecida su capacidad para la participación política ante la débil aceptación popular de un posible nuevo reinado desempeñado por la hija del emperador y su marido extranjero (Fausto, 1996). En síntesis, está es la Estructura de 
Oportunidades en las que cuaja la acción del movimiento popular y su ascenso.

La República no favoreció en lo absoluto a los más pobres, ni tampoco contó con su participación en la acción efectiva, ya que, la organización imperial, principalmente después de la abolición de la esclavitud, contaba con la simpatía de los más pobres e incluso con su gratitud por la liberación. Ante esta circunstancia, las clases activamente participativas de la República recién fundada tuvieron que desarrollar todo un sistema de propaganda con el objetivo de apagar los vestigios de la monarquía en Brasil: necesitó construir héroes y símbolos suficientemente atractivos para contagiar al pueblo del nuevo modelo social republicano.

b. República de la Espada y la Primera Constitución

Nace así la República de los Estados Unidos del Brasil, administrada por un gobierno provisional en 1891, cuando se crea la primera Constitución Republicana Brasileña, contando con Marechal Deodoro como presidente. Sin embargo, en el mismo año, a partir de la serie de desacuerdos en los que se confrontan el jefe del Poder Ejecutivo y el Poder Legislativo, el presidente decide cerrar en Congreso y declarar Estado de Sitio (Fausto, 1996). En el mes siguiente, tras su renuncia, el vicepresidente Marechal Floriano Peixoto asume la presidencia y gobierna hasta el 1894, período conocido por República de la Espada. Se destaca en este período algunas transformaciones institucionales, como la instalación de una República Federativa, modificando las provincias en estados con amplia autonomía económica y administrativa, aunque prohibidos de separarse del país; la institución del sistema presidencialista; la separación del Estado y de la Iglesia y; la separación de los tres poderes: Ejecutivo (presidente, vicepresidente y ministros), Legislativo (cámara y senado) y Judiciario (jueces federales). Se destaca también que los representantes de los poderes ejecutivo y legislativo deberían ser elegidos a través del voto abierto y directo, sin embargo, no incluían en el público elector a las mujeres, analfabetos, soldados y miembros de organizaciones religiosas. 
c. República Oligárquica (El Gobierno "Café con Leche”)

A partir de una relación en crisis entre los militares y la aristocracia que llega a su ápice en la República de la Espada, y la eclosión de conflictos armados alrededor del país, Prudente de Morais será el primer presidente civil en 1894, votado a través de elecciones directa.

Se inaugura así el período de la República Oligárquica, que duraría hasta el final de la República Vieja en 1930, en que la presidencia se alterna entre los partidos republicanos de São Paulo y de Minas Gerais, estados controlados económica y políticamente por los granjeros de café, el principal producto de la economía del país (70\% de las exportaciones) y productores de leche, respectivamente, ambos los estados más ricos en Brasil de la República Vieja.

Se subraye que la nueva organización brasileña poco o nada cambia en las formas de control social, ni siquiera se realizan cambios en la pirámide económica, donde se agrupan en la base el motor de la economía, y donde están presentes los extractos más pobres de la sociedad, constituida principalmente por ex esclavos y sus descendientes. Por otro lado, en las capas más altas de esa pirámide económica, se organizan oligarquías locales que asumen el poder de la máquina pública administrando los proyectos locales y nacionales siempre a favor del extracto social al que pertenecen.

No hay una revolución, o incluso grandes cambios con la Proclamación de la República, lo que hay de inmediato es la apertura de la política a los hombres enriquecidos, principalmente por la agricultura; mientras el poder de la máquina pública en el Imperio estaba concentrado en la figura del Emperador, que administraba de manera centralizadora las decisiones políticas, en la República se abría espacio de decisión para la clase enriquecida que carecía de ese poder de decisión política, luego del período en que los militares estuvieron en el poder (Faoro, 2008).

Durante el período de la República Oligárquica vigoró la política conocida por Política de los Gobernadores (o de los Estados), que consistía en un acuerdo de que el poder federal no interfería en la 
política interna de los estados y los gobiernos estatales no interferían en la política de los municipios, garantizándoles la autonomía política y la tranquilidad nacional. De esta forma, la política del café con leche consolidó el poder de las familias más acomodadas, formando las oligarquías, que permitió a la burguesía cafetera paulista controlar, en el ámbito nacional, la política monetaria y cambial a través de una política de intervención activa que garantizaba a los caficultores beneficios seguros. Para Minas Gerais, el apoyo a São Paulo garantiza el nombramiento de los miembros de la élite minera para cargos en el área federal y fondos para obras públicas, como la construcción de ferrocarriles y otras obras de infraestructura en ambos los estados.

Los paulistas y los mineros ocupaban los cargos de presidente de la República, vicepresidente y el control de diversos ministerios. En los Estados, pocas familias ocupaban los cargos de Gobernador del Estado, las secretarías, la alcaldía de la capital, la jefatura de Policía Estatal, la dirección de la Prensa Oficial, la presidencia de los Bancos Estatales y la presidencia de la Asamblea Legislativa. Estos rasgos del poder político que van de la mano de la élite se mantendrían en el país hasta los días actuales, aunque se presentarán de otras formas a partir de la segunda etapa democrática.

Sin embargo, la población a pesar de estar excluida de la participación política del país, principalmente fuera de los estados dominantes, no se quedó pasiva ante la monopolización del poder. Durante las tres décadas de la República Vieja, además de las revoluciones citadas del período del gobierno militar, sucedieron por todo el país otras revueltas, como por ejemplo: la Guerra de Canudos (1896-1897, Bahia), la Revolta da Vacina (1904, Rio de Janeiro), Revolta da Chibata (1910, Rio de Janeiro), Guerra do Contestado (1912-1916, Paraná y Santa Catarina), Revolta de Juazeiro (1914, Ceará) y Coluna Prestes (1925-1927, diversos estados). Los movimientos contestaban las estructuras y dinámicas creadas por la aristocracia en la República y buscaban una mayor participación popular en el sistema político y económico (Fausto, 1996). 
La política café con leche fue disuelta en 1930, después de doce presidentes, diez del partido paulista o minero. En esta fecha, el presidente Washington Luís decidió no alternar el poder con el partido minero sino apoyar la candidatura de un compañero de su partido, hecho que desagradó a la élite minera que pasó a aliarse con la élite del estado del Rio Grande do Sul, con los que proponen a Getúlio Vargas como candidatura alternativa a la presidencia.

La República Vieja marca el primer capítulo de la historia de la República y un período en que se desarrollan, aunque tímidamente, prácticas democráticas de representación y elección de gobierno. Era la primera vez que había un proceso para elección de jefe del poder ejecutivo a través del voto popular, aunque el resultado de este proceso no representase la voluntad de la población en su mayoría.

Sin embargo, Therborn (1980) destaca que la democracia, como forma de Estado, consiste en un gobierno elegido representativamente por un electorado consistente en la totalidad de la población adulta, cuyos votos valen lo mismo y que son libres para votaren sin que su preferencia resulte en intimación por el aparato del Estado. A partir de esto, es importante subrayar que las elecciones ocurridas en el período de la República Vieja fueron directas, no obstante, no contaban con amplia participación popular, una vez que el promedio de participación en el período fue de alrededor de $2 \%$ de la población. Así mismo, las elecciones eran marcadas por la grande influencia de los coroneles, personas influentes responsables por el poder ejecutivo e incluso militar en los municipios, que practicaban fraudes electorales y obligaban las personas bajo su influencia a votaren en el candidato apoyado por el coronel, voto este que tampoco era secreto.

Utilizamos las palabras de Comparato (2003), que expresa su opinión al respecto del origen de la democracia, para ejemplificar la agenda de grande parte de los que buscaron la transición brasileña del Imperio hasta la República:

"La democracia moderna, reinventada casi al mismo tiempo en América del Norte y Francia, fue la fórmula política encontrada por la burguesía para extinguir los antiguos privilegios de los dos principales 
estamentos del antiguo régimen -el clero y la nobleza- y hacer el gobierno responsable ante la clase burguesa. El espíritu original de la democracia moderna no fue, por lo tanto, la defensa del pueblo pobre contra la minoría rica, sino la defensa de los propietarios ricos contra un régimen de privilegios estamentales y de gobierno irresponsable." (Compararto, 2003, p.50).

\section{Capítulo 2: Era Vargas (Segunda y Tercera República) 1930 - 1945}

a. La Revolución de 1930

Con la inestabilidad política generada a partir del rompimiento de la política café con leche, otro estado surge como actor en el paisaje nacional, el Rio Grande do Sul. Este estado, juntamente con el disidente Minas Gerais, el estado de Paraíba y partidos políticos de oposición de otros estados, crea la Alianza Liberal para hacer oposición a la candidatura del Partido Republicano Paulista en las elecciones de 1930. En esta época el país contaba con 20 estados, siendo que amplia mayoría (17) apoyaban el candidato del gobierno de la época.

La elección de marzo de 1930 fue marcada por polémicas, así como fueron todas las elecciones anteriores, debido a la práctica de influencia de votos, acusaciones de fraudes, ausencia de un órgano de justicia electoral, etc. Después de más de dos meses de cálculo de los votos, Julio Prestes, candidato del partido en el poder, fue elegido para la presidencia. Sin embargo, los participantes de la Alianza Liberal rechazaron el resultado y se negaron a aceptar el oponente de Getúlio Vargas como presidente elegido. Desde entonces, comenzaba una conspiración entre los estados de la Alianza Liberal para no permitir que el candidato votado asumiese la presidencia.

Fue así que en el día 3 de octubre de 1930 se pone en marcha un movimiento armado desde el Rio Grande do Sul y Minas Gerais con destino hacia la sede del gobierno nacional, Rio de Janeiro. En menos de un mes la revolución ya había conquistado casi todos los estados del país, por lo tanto, ya no estaban más bajo control del gobierno 
federal. Por fin, en el día 24 de octubre el presidente Washington Luís es detenido por el ejército que asume el gobierno a través de una junta militar, poniendo fin en el régimen oligárquico a través de las armas.

b. Segunda República (1930-1937)

El día $1^{\circ}$ de noviembre de 1930 fue marcado por ser el día en que Getúlio Vargas, derrotado en las elecciones de marzo del mismo año, recibe el poder nacional de la junta militar, se tornando el jefe del Gobierno Provisorio con amplios poderes.

Durante el período del Gobierno provisorio, Getúlio no recibe el título de Presidente de la República, sino que de jefe del gobierno. Como principales acontecimientos, se destacan la revocación de la constitución de 1891 y el gobierno a través de decretos, la disolución del congreso nacional y estadual, la intervención federal en los gobiernos estaduales, a través de la nominación de personas para el Poder Ejecutivo en todos los estados, con excepción de Minas Gerais y la creación del Ministerio del Trabajo, Industria y Comercio en su primero mes de gobierno (Fausto, 1996).

Todas estas transformaciones resultan un importante cambio en la escena política del país, puesto que, coloca fin a la hegemonía de las oligarquías rurales de São Paulo y Minas Gerais. No obstante, es fácil de identificar los trazos dictatoriales del Gobierno Provisorio.

Como respuesta al golpe militar que tomó el poder federal y al Gobierno Provisorio, se instaura la Revolución de 1932 (Revolución Constitucionalista) en el estado de São Paulo que tenía el sentimiento de revancha contra el gobierno federal. Oposicionistas y antiguos apoyadores del movimiento de 1930 se unen contestando los actos de Getúlio Vargas que son considerados dictatoriales y enfrentan el ejército durante tres meses, hasta su derrota en octubre de 1932; aún derrotado, el movimiento acelera la adopción de los procesos democráticos a nivel federal (Faoro, 2008).

En el año siguiente, 1933, acontecen las elecciones para la Asembleia Nacional Constituinte, responsable por la elaboración de una nueva constitución para el país. Es importante el avance en los procesos democráticos marcados por esta elección, ya que, por 
primera vez las mujeres tienen acceso al voto a nivel nacional, como también es la primera elección realizada después de la creación de la Justicia Electoral, ayudando en la seguridad del proceso.

En julio de 1934 una nueva constitución es promulgada y en la misma fecha ocurre una elección indirecta para la presidencia de la República en que Getúlio Vargas es elegido presidente por el Congreso Nacional para un mandato hasta el 1938.

c. El Estado Nuevo / Tercera República (1937-1945)

En noviembre de 1937, algunos meses antes de la elección del siguiente presidente de la República, Getúlio Vargas, a través de un golpe de estado, instituye el Estado Nuevo, determina el cierre del Congreso Nacional y otorga una nueva constitución, la Constitución de 1937 que lo confiere poder total del Poder Ejecutivo e incluso poder para nombrar los jefes del Ejecutivo de cada estado. La justificación para el golpe de estado fue el estado de pre-guerra que vivía el país, de acuerdo con su presidente, y la amenaza comunista propagada para la población (Faoro, 2008).

En diciembre los partidos políticos son extintos y las banderas de los estados quemadas en una grande ceremonia, pues el Estado Nuevo predicaba el contacto directo entre el gobierno y la población, así como la unión del país en una solo nación. El Estado Nuevo es caracterizado por la centralización del poder, el nacionalismo, el anticomunismo y el autoritarismo, incluso con la censura de prensa, en línea con otros movimientos políticos del Occidente en la misma época.

Los años siguientes, aunque bajo un gobierno dictatorial, son marcados por obras de infraestructura alrededor del país y de la creación de organizaciones, instituciones y leyes que hasta la actualidad están presentes en el país. Se destacan las empresas estatales Vale do Rio Doce (minería) y Companhia Siderúrgica Nacional (acería), la Justicia del Trabajo, los Código Penales, Laborales y de Tráfico, así como la institución del salario mínimo. Durante este período, aunque con carácter autoritario, Getúlio Vargas fue un político bastante 
populista, carismático y con frecuente contacto directo con la población trabajadora.

A partir de 1942 empiezan movimientos en contra al Estado Nuevo y su forma de represión a la libertad. El período post Segunda Guerra Mundial es marcado en Brasil por el descontento entre los militares brasileños enviados para luchar contra regímenes dictatoriales, mientras los mismos rasgos del sistema ocurrían en el país. Con la victoria de los Aliados, hay un movimiento a favor de la libertad que sacudió el Estado Nuevo y empieza el movimiento de apertura política.

En mayo de 1945 se planifican elecciones presidenciales para el final del mismo año y se legalizan los partidos políticos nuevamente. No obstante, en octubre Getúlio Vargas es destituido de su cargo por los mismos militares que lo habían ayudado a llegar al poder en 1930. El jefe del Poder Judiciario se mantiene en el poder del Ejecutivo, en común acuerdo con los candidatos a la presidencia, hasta que las elecciones de diciembre se efectuaran.

\section{Capítulo 3: La República Populista (Cuarta República) 1945 - 1964}

Después de casi diez años de un régimen dictatorial y quince años después de las últimas elecciones presidenciales directas, en diciembre de 1945 la población brasileña elige nuevamente un presidente. Las elecciones de 1945 fueron un marco en la historia de la democracia de Brasil debido a la confiabilidad de sus resultados, una vez que no hubo acusaciones de fraude ni tampoco la oposición cuestionó los resultados, hecho inédito hasta entonces en la República. Otro factor importante fue el acceso de las mujeres al voto y a la amplia participación popular; mientras la elección presidencial directa anterior había sumado menos de dos millones de votos, la elección de 1945 sumó seis millones, representando más de 10\% de la población de la época (Fausto, 1996). El militar Gaspar Dutra, ex Ministro de la Guerra y candidato apoyado por Getúlio Vargas, que aun gozaba de 
popularidad con la población, asumió la presidencia de la República en enero de 1946 juntamente con una Asamblea Nacional Constituyente.

En septiembre del mismo año se promulga la nueva Constitución de 1946, caracterizada principalmente por rescatar ideas contenidas en la Constitución de 1934. Es así, como Brasil fue definido como una República Federativa, estableciendo atribuciones para la unión, los estados y los municipios, así como se fija las atribuciones del poder Ejecutivo, Legislativo y Judiciario. El gobierno de Dutra se caracteriza por la represión al comunismo y a los derechos de los trabajadores, por tanto, en 1947 es suspendido el registro del Partido Comunista, se interviene en centenas de sindicatos y se dificulta las manifestaciones de huelga.

Tres años después, transcurren las elecciones para nombrar el siguiente presidente de la República, trayendo de vuelta un conocido de los brasileños: Getúlio Vargas, que, tras salir de la presidencia en 1945, el ex dictador se mantuvo en la política, trabajando como senador por São Paulo y Rio Grande do Sul.

Esta elección de 1950 fue caracterizada por la primera participación de medios y de un horario electoral, principalmente a través de la radio y eso llevó a una participación mayor del electorado brasileño; más de ocho millones en contra los seis de la elección anterior. Se subraye que Brasil vivía un momento de transformación social y económica, esencialmente por la expansión de las industrias, lo que ocasionó una gran migración de la población rural a las ciudades; a medida que la población urbana crecía, el grado de politización y participación de estas personas crecía también (Faoro, 2008).

El gobierno de Vargas fue tumultuado en función de medidas administrativas realizadas y por las acusaciones de corrupción en su gobierno que generó una pérdida del apoyo de sectores de la sociedad como los militares y élite. No obstante, algunos de los hechos a destacar son: el reajuste de $100 \%$ en el salario mínimo que causó desagrado en grupos sociales, intervenciones estatistas, la protección al petróleo con la creación de PETROBRAS y el Banco Nacional de Desenvolvimento Econômico e Social (BNDES). En 1954 un 
atentado contra la vida de Carlos Lacerda, gobernador del Rio de Janeiro y fuerte opositor de Vargas, que culminó con la muerte de un mayor de la Fuerza Aérea Nacional, desencadena una crisis en el gobierno, una vez comprobada la autoría del crimen haber sido de miembros de la guarda personal de Vargas. A partir de este acontecimiento, la presión de los partidos opositores, prensa y ejército para que el presidente renuncie a su mandato llega a su ápice en ese entonces. Vargas, por entender que su renuncia podría debilitar las instituciones, el orden y la constitución, a partir de una tomada del poder por los militares, decide salir de la vida para entrar en la historia y se suicida en el 24 de agosto de 1954.

El suicidio de Vargas causa una gran conmoción popular en el país con millares de personas saliendo a la calle saludar el "padre de los pobres". De esta forma, Vargas salía de la posición de acusado para de víctima. Además, el suicidio de Vargas adía un posible golpe de estado que se planteaba en el horizonte y tranquiliza los militares a través de la llegada de su vicepresidente, Café Filho, un político conservador, a la presidencia de la República.

La popularidad de Vargas, que crece tras su trágica muerte, influenciaría en la siguiente elección a la presidencia, resultando en la victoria de Juscelino Kubitschek (JK), su heredero político, en 1955. El gobierno de JK, elegido a partir de elecciones directas, es marcado por su característica desarrolladora, con la llegada de diversas empresas internacionales al país, obras de infraestructura y la transferencia de la sede del gobierno desde Rio de Janeiro para Brasília, ciudad construida específicamente para este objetivo. Aunque el gobierno fuera también caracterizado por la convivencia democrática, hubo muchas acusaciones de corrupción en su mandato. Con el pasar del tiempo, al pasar su puesto de presidente a Janio Quadros, en enero de 1961, JK se tornó el primer presidente civil a terminar su mandato dentro de plazo determinado por la Constitución desde Artur Bernardes en 1926 y que ocurriría solamente treinta y ocho años después, en 1999.

Del último período del gobierno democrático antes de la dictadura militar, que empezaría en 1964, se destaca que el primero 
presidente, Janio Quadros, renuncia a su puesto siete meses después de asumirlo. El rápido gobierno de Quadros fue marcado por actos relacionados con la política externa y financiera, así como debates morales y conservadores como la prohibición de biquinis en las playas brasileñas. Los motivos de su renuncia no se quedaron claros, aunque se diga que ha sido solamente una tentativa de ganar poder con el Congreso una vez que este rechazaría su pedido para no dejar su vicepresidente, relacionado a la izquierda, acceder al poder. Sin embargo, su pedido fue aceptado y generó una crisis política en el país, en agosto de 1961 (Fausto, 1996).

El vicepresidente, João Goulart (Jango), que había sido Ministro del Trabajo del gobierno Vargas y por lo tanto cercano de las políticas en favor de los trabajadores, amenazaba los sectores más conservadores de la política. De hecho, su nombre era fuertemente relacionado a la amenaza comunista y, por suerte o azar, en el día que Quadros renunció, Jango estaba en viaje a la China comunista, lo que fue utilizado como justificativa por aquellos que no querían que él asumiera el cargo de presidente.

Los militares, la prensa de derecha y los políticos conservadores no aceptaban que Jango fuera presidente y empezaran movimientos contrarios, de forma que Jango tuvo que se resguardar en Uruguay, después de su viaje a China, por la definición de su pose o no. En ese momento, empezó en el estado del Rio Grande do Sul, un movimiento llamado Campanha da Legalidade, en el que, a partir de la iniciativa del gobierno gaucho de garantir la legalidad de pose del vicepresidente, la población se adhirió y millares de personas salieron a la calle para defender el mandato de Jango. El conflicto entre los militares y el gobierno gaucho, con apoyo de la población, por poco no empezó una guerra civil en el país.

La solución propuesta por el Congreso fue la adopción del parlamentarismo como sistema de gobierno, en que Jango tomaría su rol como presidente, no obstante, se elegiría un primero ministro para ser el jefe del Poder Ejecutivo. Un año y medio después, en enero de 1963, a través de un referéndum, el sistema presidencialismo fue 
elegido por la población y el puesto de primero ministro fue extinto, llevando a Jango a gobernar con plenos poderes.

Entre 1963 y 1964 avanza el discurso de una extrema derecha hacia otros sectores de la sociedad, uniendo los militares, la iglesia católica y la élite de la sociedad civil por el miedo a que Brasil se transformara en una dictadura socialista o comunista, a partir de una crisis económica y por medidas del gobierno que era vistas como comunistas, como la reforma agraria y urbana, dando fuerza al movimiento anti el presidente Jango (Batista, 2017).

En marzo de 1964 el presidente, en una manifestación con más de trescientas mil personas, desencadena una crisis en el país a partir del decreto de la nacionalización de las refinerías privadas de petróleo y de la expropiación, para fines de reforma agraria, de propiedades a los márgenes de ferrocarriles, carreteras y zonas de riesgo de azudes públicos. En el mismo mes también empieza otra manifestación llamada: la Rebelión de los Marineros, que aumentaría la presión en el gobierno de Jango hasta que finalmente el 31 de marzo de 1964, el presidente es sacado de su puesto y empieza el régimen militar en Brasil.

\section{5 \\ Capítulo 4: La Dictadura Militar (Quinta República) 1964 -}

El período comprendido entre el 01 de abril de 1964 y el 30 de marzo de 1983 no es abordado en este artículo. Aunque cuente como una etapa de la historia republicana brasileña - la quinta parte, más precisamente - el período dictatorial ha sido marcado por la interrupción de los procesos democráticos a partir del cercenamiento de derechos políticos e individuales, la amplia utilización de la fuerza por el Estado y el fortalecimiento del poder ejecutivo concentrado en las manos de un grupo militar autoritario.

Si este trabajo se propone a presentar los altos y bajos de la historia de la democracia en Brasil República, las más de dos décadas de dictadura en el país representan el período en que el concepto de gobierno del pueblo estuvo más lejos de la realidad. El final de las 
elecciones directas, la cancelación de partidos políticos de oposición, la represión a los movimientos sociales, el inicio de la censura en los medios y el arte, el autoritarismo y, por fin, la persecución, tortura y muerte de cientos de personas por el gobierno militar (Mezarobba, 2011) demuestran lo que de menos democrático se puede ser observado en los países occidentales del siglo XX. El período dictatorial es aquí destacado como una triste parte de la historia del Brasil República.

\section{Capítulo 5: La Nueva República (Sexta República) 1985 - 2018}

a. La (Re)Democratización (1985-1989)

El primer capítulo de la Nueva República empieza todavía durante la dictadura militar, en el 31 de marzo de 1983, con la primera manifestación pública organizada de cien personas en una pequeña ciudad del estado de Pernambuco, la cual daría inicio al Movimiento Diretas Já. Este movimiento, que crece a partir de la unión del movimiento estudiantil, huelgas de obreros, manifestaciones de sindicatos y la clase media, llega a un millón y medio de personas en una manifestación en abril de 1984. En este entonces, se destaca la participación de la misma clase media que salía a las calles en 1964 para gritar en contra el comunismo y a favor del sueño americano, ahora mucho más pobre, desempleada, y, uniéndose a los miserables, los favelados, sindicalistas, estudiantes, intelectuales perseguidos, y al pueblo en general, rogando por democracia. Fue así como el movimiento Diretas Já tuvo gran importancia en la redemocratización de Brasil y sus líderes pasaron a formar la nueva élite política brasileña (Fausto, 1996).

La dictadura militar estaba bajo el ataque de innumerables sectores de la sociedad, la comunidad y la prensa internacional y las organizaciones de derechos humanos, así como las denuncias de torturas, asesinatos, y principalmente la impunidad de los agentes que practicaban estos actos, estaban cada vez más en destaque en los medios internacionales. No obstante, una de las principales causas de la pérdida de popularidad al Régimen Militar, fue el alta inflacionaria 
en los últimos años de la dictadura, que causó un fuerte desgaste entre el gobierno federal y la sociedad civil; a pesar del fuerte crecimiento económico de la década de 1970, en el inicio de los años 80 la economía estaba estancada (Fausto, 1996).

En un contexto de desgastes y presión civil, las elecciones presidenciales de 1985, aunque fueron indirectas, tuvieron participación del marketing político, con manifestaciones y la creación de músicas y símbolos. En enero de 1985, Tancredo Neves fue elegido, a través de un colegio electoral, el presidente de la República con la promesa de que estas habían sido las últimas elecciones indirectas del país, sin embargo, Neves murió antes de la pose del puesto, que fue ocupado por su vicepresidente, José Sarney.

Tres años después, en 1988 se aprobó una nueva Constitución Brasileña, que restableció principios democráticos en el país. Con la promulgación de la nueva Constitución de 1988, Brasil entró finalmente en el camino hacia la democracia plena, de hecho, de derecho, con el pluripartidismo y elecciones directas para cualquier cargo electivo del país. Así que, en 1989 se realizan las primeras elecciones presidenciales directas desde 1960 que eligen Fernando Collor como presidente.

Collor había sido gobernador del pequeño estado de Alagoas y no era conocido en el resto del país, pero, a través de una campaña agresiva basada en la promesa de combatir la corrupción, de la construcción de una imagen de líder joven y dinámico, que vendía una imagen de político de derecha progresista y con el apoyo de sectores que temían la victoria del candidato del PT, Luiz Inácio da Silva, Collor llega al puesto de Jefe del Poder Ejecutivo.

b. Las denuncias contra el primer presidente democráticamente elegido después de la dictadura militar

En el desarrollo del gobierno, el presidente Fernando Collor tomó varias medidas económicas, como el cambio de moneda, la creación de impuestos y reducción de incentivos, aumento de tasas públicas, entre otras, que quedaron conocidas por "Plan Collor". La medida de mayor repercusión fue el préstamo obligatorio al gobierno de todo valor 
mantenido en el ahorro que excediera los 50.000 cruceros (moneda de la época), que se quedó conocida popularmente como confiscación del ahorro, y generó amplia indignación popular (Fausto, 1996).

A mediados de 1991 comenzaron a surgir en la prensa denuncias de irregularidades relacionadas a personas cercanas del presidente Collor, como ministros y amigos, luego, en mayo de 1992 su hermano revela en una entrevista, un esquema de corrupción liderado por el ex tesorero de la campaña electoral, entre otros hechos comprometedores para el presidente.

En este contexto, se organiza desde el movimiento estudiantil, el movimiento llamado Caras Pintadas, en que millares de personas, por todo el país, salieron a la calle exigiendo la renuncia del presidente "corrupto". La conmoción popular aumentaría y acompañaría el proceso de impeachment hasta llegar a millones de personas involucradas cuándo, en diciembre de 1992, Collor renuncia la presidente de la República, antes de ser condenado.

A partir de esta fecha, el país sería gobernado por su vicepresidente, Itamar Franco, hasta las próximas elecciones presidenciales de 1993. Es en este gobierno que en abril de 1993 fue realizado, de acuerdo con lo que estaba previsto en la Constitución de 1988, un referéndum para elegir la forma y el sistema político del país. La República ganó de la Monarquía (66\% x 10\%) y el presidencialismo ganó del parlamentarismo (55\% x 25\%).

c. El Gobierno Fernando Henrique Cardoso -FHC (1995-2002)

Al finalizar el mandato de Itamar Franco, en 1994, el proceso democrático continúa y el país elige, a través del voto directo, tres presidentes que serán reelegidos una vez cada uno, Fernando Henrique Cardoso -FHC (1995-2002), Lula da Silva (2003-2010) y Dilma Rousseff (2011-2016). FHC había sido Ministro de la Hacienda en el gobierno precedente y su elección representó la continuación de la administración anterior.

Sus principales marcas fueron la consolidación del Plan Real, que fue el plano económico iniciado en el gobierno anterior con el objetivo de contener la inflación, la reforma del Estado a través de la 
privatización de empresas estatales, la creación de las agencias reguladoras y la introducción de programas de transferencia de renta como el Bolsa Escuela, además de la creación de una nueva moneda, el real brasileño. Por otra parte, sus logros fueron principalmente mantener el orden político y económico del país que cada vez más abría su economía hacia fuera (aunque tímido, hubo un aumento en la tasa media de crecimiento del PIB que en su período fue de $2,3 \%$ al año, con destaque para el primer mandato) y también el aumento en el acceso a la enseñanza básica, la disminución del analfabetismo y la valorización del salario mínimo. No obstante, FHC sufrió diecisiete denuncias que, si comprobadas, podrían llevarlo a su destitución, pero todas fueron archivadas por los presidentes de la Cámara de Diputados, encerrando el proceso (Batista, 2017).

En su segundo mandato, a partir de 1999, la economía del país empieza a perder fuerza motivada por una crisis de cambio que resultó en una disminución en la tasa de crecimiento y en el aumento del desempleo y de la deuda pública. Este contexto favoreció el crecimiento del movimiento de oposición que se fortalecía con candidatos a gobernar el país en las primeras elecciones presidenciales del siglo 2000. Por otro lado, había también un contexto de desconfianza, en el que la élite económica del país temía las medidas a ser tomadas por un candidato de izquierda si éste ganaba la elección. No obstante, el Partido dos Trabalhadores (PT) supo alinearse con partidos de izquierda y derecha, liberales y conservadores, y llegó al poder a partir de la elección de Luis Inácio Lula da Silva en las elecciones presidenciales de 2002.

d. Los Gobiernos del Partido dos Trabalhadores - PT (2003-2016) El 1 de enero de 2003 fue marcado como la fecha en que por primera vez un partido de izquierda llega al puesto más alto del Poder Ejecutivo, como también, fue la primera vez, desde 1961, que un presidente democráticamente elegido pasa el cargo a otro igualmente elegido. Las elecciones de 2002 fueron las primeras que tuvieron dos turnos para elegir el presidente y llegaron a la cifra de 95 millones de votos, mayor cantidad hasta entonces. 
En los dos gobiernos de Lula se destaca el aumento de los programas sociales, la construcción de universidades públicas, disminución del desempleo, la reducción de la pobreza y de la desigualdad social, y la proyección de Brasil en la política internacional y económica, a través de los BRICS. Por otro lado, los gobiernos de Lula también sufrieron acusaciones de corrupción, siendo el caso más conocido el Escandalo do Mensalão, en el que se denunció un esquema de compra de votos de diputados en el Congreso y el financiamiento de campañas por "Caixa 2".

El Gobierno de Lula termina su mandato con la aprobación récord de la población, con un número superior al 80\% de evaluación positiva, lo que facilita la elección de su sucesora, Dilma Rousseff, para el cargo de presidente de la República.

La primera mujer como jefe del Poder Ejecutivo da continuidad en los programas del gobierno anterior, el cual había sido ministra, y consigue mantener la popularidad del gobierno en sus primeros años. Sin embargo, la eclosión de las manifestaciones de junio de 2013 marca su primera crisis institucional. En esta fecha, a partir del movimiento estudiantil que contestaba el aumento en las tarifas del transporte público municipal, empiezan en el país numerosas manifestaciones populares, llevando millones de personas a salir por la calle en todos los estados para contestar los aumentos en las tarifas del transporte, la truculencia de las policías militares estatales, además de reivindicaciones sobre condiciones de salud, educación, seguridad y la realización de la Copa do Mundo 2014 en el país. La histórica ola de protestas generó una gran pérdida de la popularidad hacia presidenta, los gobernadores, alcaldes, diputados y de la mayoría de los partidos del país (Menezes, 2017).

A pesar de una popularidad cada vez menor junto a la población, Dilma todavía consigue vencer las elecciones de 2014 y se reelige presidente de la Republica, así las elecciones de 2014 marcaron una bipolarización ideológica en todo el país, con fuertes campañas políticas electorales y un resultado de elección a presidente sin amplia mayoría: Dilma Rousseff fue reelegida con 54,5 millones de votos, 
representando el 51,64\% contra 48,36 el porcentaje de su oponente, Aécio Neves, candidato de centro derecha, representante de empresarios, de los grandes medios y de la clase media/alta del país. Además de iniciar el mandato con un país dividido políticamente, con los partidos de derecha no aceptando el resultado y solicitando el recuento de votos, la presidenta electa tuvo retos de gobernabilidad con uno de los Congresos Nacionales más reaccionarios de todos los tiempos, representado principalmente por bancadas de extrema derecha relacionadas a sectores como el agro negocio, la policía y el ejército y la religión. Por ende, el inicio de una crisis política con el Poder Ejecutivo enfrentando dificultades de alineamiento con el Poder Legislativo, principalmente la Cámara de Diputados Federales.

A partir de este contexto, las tensiones políticas se profundizaban y el empeoramiento de las relaciones se acentuaba, creando un imaginario social de desaprobación a la democracia, a los partidos políticos y a la propia política. Las artificiales y superficiales coaliciones políticas entre diferentes partidos con intereses meramente mercantiles de poder y fondos públicos, que estaban en todas las gestiones de los presidentes anteriores, llegaban a un límite en el segundo gobierno Dilma (2015-2016), siendo el contexto de fondo para el inicio del proceso de impeachment (Menezes, 2017).

e. El Impeachment de 2016

En 2016, en el segundo año de su segundo mandato, la presidenta Dilma se aleja de su cargo, nuevamente a través de un proceso de denuncia y revocación política, dejando lugar para que su vicepresidente, Michel Temer, fuera el responsable del Poder Ejecutivo hasta el fin del mandato. Cabe destacar brevemente que, a diferencia del caso anterior generado a partir de actos individuales de crimen para beneficio propio del presidente en acción, el impeachment de 2016 es causado oficialmente a partir de actos administrativos de un gobierno.

A principios de 2014, se inició una fuerza de trabajo del Ministerio Público Federal, conocida como "Operación Lava Jato", que al investigar el escándalo de corrupción y de desvío de dinero 
público más grande de la historia del país, involucrando a diferentes políticos, banqueros y ejecutivos de algunas de las mayores sociedades empresariales nacionales, transformó una investigación de desvío de dinero de Petrobras en la mayor operación mediática influyendo directamente los resultados políticos de la historia brasileña reciente (Menezes, 2017). Se destaca que uno de los puntos relevantes de la Lava Jato es la utilización del procedimiento llamado "delación premiada", que consiste en que un acusado denuncie a otros participantes del crimen a cambio de beneficios para su pena. Estas denuncias de acusados tuvieron gran repercusión en los medios y en la política nacional, ya que, aunque los acusados de Lava Jato denunciaran a otros sin ningún tipo de prueba, estos nuevos denunciados eran expuestos, a través de los grandes medios, como "grandes ladrones" la sociedad. En el contexto brasileño, el Estado democrático de derecho que salvaguardaba la presunción de inocencia fue sustituido por un estado de delación, histeria y pre-juicios sin pruebas y, por veces, sin siquiera elementos acusadores con alguna solidez procesal (Menezes, 2017).

Es importante subrayar el papel de los medios como formadores de opinión pública a partir del fomento de un discurso ideológico selectivo que servía como narrativa para el proceso de ataque y sanción al gobierno. La narrativa de la "corrupción" fue el argumento de identificación negativa proyectada exhaustivamente por los medios de comunicación y, en función del discurso mediático, sólo los miembros del PT estaban directamente involucrados en corrupción. Fue así que la Operación Lava Jato funcionó como una especie de ornamento sagrado para disparar a los petistas en la hoguera de la inquisición mediática, al mismo tiempo que nombres de otros partidos eran relativizados o simplemente negados (Menezes, 2017). A partir de esto se subraya el pensamiento de Chauí (2013), que expresa que la fuerza de imposición de ideas y administración de mundo está ligada al deseo de las clases dominantes de mantener siempre en su control los destinos de la sociedad, ya que las ideas dominantes de una época son las ideas de la clase dominante de esa época. 
Al igual que la evolución de la Lava Jato, que particularmente mantenía bajo los focos a nombres ligados al partido de la presidenta de la República, el PT, y que también perdía base de sustentación en cada nueva denuncia divulgada por los medios, el gobierno plantea un programa de ajuste fiscal neoliberal que culminaría con el sesgo de recesión económica para los sectores productivos. Fue así que, aliado al cuadro internacional de caída del precio del petróleo y la devaluación del real frente al dólar, la crisis de 2008 finalmente llegaba a Brasil, siete años más tarde.

Así, la crisis política, que nació a partir de las elecciones de 2014 y ganó repercusión y adhesión de las clases sociales por la Operación Lava Jato, ahora estaba acompañada de otro elemento crucial favorable: la crisis económica.

En 2015, con el inicio del auge de la crisis económica, que condenaría el país a retrocesos en el PIB en los años siguientes y al aumento de las tasas de desempleo, empiezan a tomar cuerpo cada vez mayor las protestas populares contra el gobierno. El ciudadano común, que se alienaba a la crisis política, ahora había localizado en su mente, por la narrativa contextual fomentada por los medios de la masa, un discurso muy convincente para protestar: la crisis económica causada por la corrupción del gobierno (Menezes, 2017). Con el llamamiento de movimientos por el fin de la corrupción, grandes marchas públicas, reuniendo, generalmente, grupos de clase media, salían a las calles, a los domingos, con camisetas de la selección brasileña y rostros pintados de verde y amarillo, pidiendo el fin del gobierno PT. Aunque todavía no había motivos justificados para un proceso de ataque al gobierno, el apoyo popular facilitaba que grupos políticos interesados organizasen un plan para el derrocamiento de la presidenta.

El proceso de impeachment de 2016 tuvo gran repercusión nacional e internacional y corroboró para la división de la sociedad, con voluminosas manifestaciones públicas favorables al impedimento, pero también un cuantitativo razonable de personal manifestándose a favor del mantenimiento del mandato de la presidenta electa. Se reunió 
una articulación que involucró un amplio segmento de la élite nacional, mezclando a los sectores parlamentarios, grandes medios, empresarios, sistema financiero y sectores de la clase media de mayor poder adquisitivo a través de campañas ostensibles para desestabilizar el mandato presidencial. Sin embargo, no fue un proceso acompañado por el pleno consenso y, una vez que los mayores juristas brasileños se posicionaron contra el derrocamiento de la presidenta, algunos sectores de izquierda lo calificaron como un Golpe Parlamentario (Peixinho, 2017).

Hay todavía quien ve referencias del proceso de golpe de estado de 1964, que culpó en más de 21 años de dictadura militar, con el proceso de impeachment de 2016. Las fuerzas que actuaron en el golpe de 1964 resurgieron con diferencia en las iniciativas políticas sectoriales. Si en 1964 los militares asumieron la postura del viejo golpista con tanques, ahora cedieron lugar para un peligroso protagonismo de los actores jurídicos en concomitancia con el legislativo y el ala conspiratoria golpista dentro del propio Poder Ejecutivo (Batista, 2017). Ambos los presidentes fueron depuestos de sus cargos políticos por una oposición conservadora que los asoció al comunismo y al mismo tiempo fragilizó las instituciones democráticas brasileñas.

El anticomunismo brasileño en 1964 logró éxito por la actuación de la opinión pública de la misma forma como hubo con el antipetismo en 2016. El ex militar y ex historiador Nelson Sodré (1997), analiza que el golpe militar de 1964 podría haberse evitado si el país tuviera realmente instituciones que fueran democráticas y sólidas. Es en este sentido que cobre relevancia de, en los días actuales, garantizar que no haya ruptura en el proceso democrático.

La sociedad brasileña, como resultado del impeachment de 2016, se ve frente a un Poder Ejecutivo que asume, en lugar de un gobierno de que formó parte y que ayudó a derribar, con un plan de gobierno en desconexión con las propuestas presentadas a la población y que le aseguró la elección en 2014. Sin la autoridad de un gobierno elegido democráticamente, la gestión de Michel Temer anuncia cambios 
radicales a partir de reformas estructurales que impactan en los próximos gobiernos, como el Nuevo Régimen Fiscal (también conocido como la PEC Techo de los Gastos), la Reforma Laboral y la Reforma de la Previdencia, así como proyectos de privatización de empresas estatales. Ninguna de esas propuestas fue debatida por la sociedad y tampoco pasarían por el filtro del voto popular si fuera un proyecto político.

De acuerdo con Bernadón (2016), en el contexto de 2016, el grupo político que sube al poder emprende sus acciones de forma autoritaria, de acuerdo con los intereses de los sectores que lo ayudaron a conquistar el gobierno, para aplicar contrarreformas que benefician directamente al gran capital y en detrimento de los trabajadores. Esta política de gobierno, totalmente contraria a la empleada en los años anteriores, aunque sin credibilidad política por contar con una gran cantidad de miembros denunciados ante la justicia, abre espacio para el crecimiento de un movimiento autoritario y de derecha que logrará su apogeo en la elección presidencial de 2018.

f. La elección presidencial de 2018 y el avance de la extrema derecha como alternativa al gobierno del PT

La elección presidencial de 2018 tuvo algunas reglas diferentes en relación a las elecciones anteriores, como la veda de la financiación empresarial a los candidatos y una campaña electoral con un período menor (Agencia Brasil, 2018). La internet ganó más espacio en las elecciones con la liberación de la recaudación por herramientas de financiamiento colectivo, pero la gran cantidad de fake news difundidas en la red fue motivo de preocupación y acción del Tribunal Superior Eleitoral - TSE (BBC, 2018).

Pese a los 13 candidatos a elección, las pesquisas de intención de voto, desde el inicio, presentaron dos políticos, antagónicos, como los más probables victoriosos: Lula da Silva y Jair Bolsonaro, representantes del PT (izquierda) y PSL (derecha). Los dos políticos, que polarizaban todavía más el ya dividido país, protagonizaron también los dos hechos que influenciarían los resultados de la elección. En abril de 2018, seis meses antes de la elección, y liderando las 
intenciones de voto a presidente, Lula fue preso, condenado a doce años de cárcel por corrupción y lavado de dinero por la operación Lava Jato. No obstante, la prisión no alteró los planes del PT de mantener Lula como el representante del partido para la elección presidencial, que solamente fue rechazado en septiembre de 2018, a un mes de la elección, por el TSE. En su lugar, su vice-candidato Fernando Haddad concurrió a presidente.

Cabe mencionar que la prisión de Lula, coincidiendo con sus resultados en las pesquisas electorales, fue considerada de carácter político por diversos grupos y órganos, nacionales e internacionales, generando diversas movilizaciones alrededor del mundo, como el Comité Internacional de Solidaridad en Defensa de Lula y la Democracia en Brasil, también conocido como el Movimiento Lula Libre. En agosto de 2018, el Comité de Derechos Humanos de la ONU solicitó a Brasil que se garantizara a Lula el derecho de ejercer sus derechos políticos mientras estuviera preso, incluyendo el acceso a los miembros de su partido y a los medios y la participación en la elección presidencial en Brasil en 2018 (Comité de Derechos Humanos de la ONU, 2018), lo que no fue reconocido.

Al mismo tiempo, Jair Bolsonaro, ex-militar y diputado federal por casi tres décadas, surgía como el único candidato que podría vencer a Lula en la elección presidencial marcada por los a favor del PT y los en contra. Este era un político poco conocido, con ideas radicales y conservadoras, a favor de la familia y religión, que amenazaba con alcanzar el poder tras la crisis política de 2016. Dos momentos son importantes de destacar en su campaña a la presidencia de Brasil: el primer hecho ocurrió un día después de que Bolsonaro apareciera como líder en las encuestas de intención de voto, en el inicio de septiembre de 2018, día en el que fue víctima de un atentado, acuchillado mientras era cargado en los hombros por simpatizantes, por lo que estuvo hospitalizado a lo largo de un mes. Mientras sus simpatizantes apoyaban su reposo médico, sus adversarios políticos lo acusaban de utilizar su situación para evitar el debate y el diálogo social (Isto É, 2018). 
El segundo hecho fue la movilización creada a partir del hashtag \#EleNão. A menos de dos semanas del primer turno de las elecciones, desde las redes sociales, empieza a formarse el movimiento \#EleNão, y tiene lugar la serie de manifestaciones que ocurrieron en decenas de ciudades del país y del exterior. Estas manifestaciones en Brasil estuvieron lideradas principalmente por mujeres en contra de la candidatura de Bolsonaro (por representar el fascismo, el racismo y la misoginia, y en contra de su discurso de odio en contra las minorías) y contaron con más de quinientas mil personas en las calles (El País, 2018).

En el día 28 de octubre de 2018, luego de votaciones en primer y según turno, marcadas por reclamaciones de fraude en urnas ( $\mathrm{O}$ Globo, 2018), registros de voto con armas (Revista Forum, 2018) e incluso incidentes como el asesinato de un capoeirista por decir que no votaría en el candidato de la extrema derecha (G1, 2018), Bolsonaro fue elegido el $38^{\circ}$ presidente de Brasil. Su candidatura, que presentó como vicepresidente un general militar, sumó más de 57 millones de votos, el 55\% del total de electores aptos a votar, y fue la más votada en 16 de los 27 estados que componen la República Federativa de Brasil.

\section{Conclusiones}

En 126 años de República, Brasil tuvo 37 presidentes - sólo un tercio de ellos (12) fue elegido directamente y terminó el mandato. Desde 1926, la proporción es aún más absurda: entre 26 presidentes, sólo 5 fueron elegidos por el voto popular y permanecieron en el puesto hasta el final: Gaspar Dutra, JK, FHC, Lula y Dilma (primer mandato). En este período, es importante observar el golpe que ha iniciado la República, el golpe que ha encerrado el gobierno oligárquico, el golpe que mantuvo Vargas en el poder, el golpe que inició la dictadura militar y dos procesos de impeachment, aunque muy distintos, en 1992 y 2016.

Para Dahl (2009), la democracia como sistema representativo de gobierno es una construcción y como toda construcción puede tener 
fases más o menos rápidas, avances o retracciones e incluso paradas. A lo largo de la historia de Brasil, analizando bajo la óptica de Dahl, hay momentos que se presentan explícitamente alejados de la poliarquía y otros exhiben elementos de ambigüedad (elecciones directas, indirectas, fraudes electorales). Sin embargo, es importante subrayar que las últimas décadas representan lo que de mejor (o menos peor) ha habido en términos de democracia en el país. Las heridas de los acontecimientos políticos de 2016 aún sangran, pero es importante que se pueda entender lo que ha pasado y cómo se pueden fortalecer las instituciones democráticas.

Lo que ha sucedido en el presente tiene raíces antiguas: en 2005, en un contexto donde por primera vez un partido de oposición gobernaba (aunque con alianzas), se dejaba atrás la crisis política de 1992, (Moisés, 2005) el apoyo al régimen democrático incluía también que en torno a los $2 / 3$ de los brasileños no confiaban en parlamentos, partidos, ejecutivos, tribunales de justicia y servicios públicos de salud, educación y seguridad. Es decir, la desconfianza en exceso y, principalmente, cuando ésta es mantenida en el tiempo, puede significar que los ciudadanos perciben a las instituciones como algo diferente de aquello para lo cual existen. En este caso, la indiferencia o la ineficiencia institucional ante las demandas sociales, la corrupción, el fraude o la falta de respeto de los derechos de ciudadanía tienen un impacto en la relación de los ciudadanos con las leyes y estructuras que regulan la vida social. Este comportamiento favorece el distanciamiento de los ciudadanos de la política y de las instituciones democráticas, debilitando el sistema que existe precisamente para que el ciudadano pueda manifestarse democráticamente. En este sentido Luttwak (1991), en su manual práctico de golpe de estado, nos alerta de algunos riesgos:

"Todo el poder, toda la participación están en manos de una pequeña élite instruida. Esta élite es alfabetizada, educada, bien alimentada y segura, diferenciando, por lo tanto, radicalmente de la amplia mayoría de los otros ciudadanos, prácticamente una raza diversa. Las masas lo 
reconocen y también aceptan el monopolio de poder de la élite, y a no ser que algún abuso intolerable acarrea una revuelta desesperada, ellas aceptarán sus políticas. También aceptarán un cambio en el gobierno, sea por los medios legales o no. Al final de cuentas, se trata sólo de otro grupo de "ellos" tomando el poder." (Luttwak, 1991, p. 37).

El marco temporal de este trabajo incluye desde el inicio de la Republica en Brasil, a finales del siglo XIX, hasta la elección presidencial de 2018. El artículo finaliza en un momento clave de la historia del país, en que, manteniendo la polarización política de la sociedad, un político de discursos de extrema derecha es elegido el líder máximo del país, poniendo fin a un mandato que se inició dentro de un ciclo de gobiernos de izquierda, pero que acabó, a partir de un proceso de derribo político del gobierno elegido, con otro gobierno y con proyectos muy distintos de aquellos que en primera instancia habían sido populares y socialmente preferidos. Este trabajo propone la mirada de un contexto amplio histórico y sociopolítico de Brasil para que el lector pueda analizar y comprender el fenómeno que es la elección de Bolsonaro, el avance de la agenda de derecha y de la extrema derecha en el país.

\section{Bibliografia}

Agencia Brasil. (2018). Pela $1^{\mathrm{a}}$ vez, campanha eleitoral não terá financiamento de empresas. Disponible en

http://agenciabrasil.ebc.com.br/politica/noticia/2018-06/pela-1a-vezcampanha-eleitoral-nao-tera-financiamento-de-empresa (Recuperado 26 marzo 2019).

Batista, A. (2017). O golpe de 1964 em comparação com o impeachment de 2016 e a afirmação de um passado que não passa. VI Congresso Internacional UFES/Paris-Est.

BBC. (2018). Eleições 2018: o que o TSE está fazendo para combater mensagens falsas? Disponible en

https://www.bbc.com/portuguese/brasil-45804824 (Recuperado 26 marzo 2019). 
Bernadon, T. (2016). O golpe de 2016: breve ensaio de história imediata sobre democracia e autoritarismo. In: Historiae, Rio Grande, 7.

Codato, A. (2006). A political history of the Brazilian transition from military dictatorship to democracy. Revista de Sociologia e Política, (25), 83106.

https://dx.doi.org/10.1590/S0104-44782005000200008 .

Comité de Derechos Humanos de la ONU. (2018). Information note on Human Rights Committee. Disponible em

https://www.ohchr.org/EN/NewsEvents/Pages/DisplayNews.aspx?News

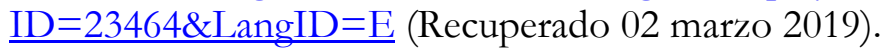

Comparato, F. (2003). A afirmação histórica dos direitos humanos. $3^{\mathrm{a}}$ ed., São Paulo: Saraiva.

Dahl, R. (2009). La Poliarquía. Madrid: Tecnos.

El País. (2018). Mulheres quebram o jejum das ruas no Brasil com manifestações contra Bolsonaro. Disponible en:

https://brasil.elpais.com/brasil/2018/09/30/politica/1538270819 523141. html (Recuperado 02 marzo 2019).

Fausto, B. (1996). História do Brasil. São Paulo: EdUSP.

Faoro, R. (2008). Os Donos do Poder: Formação do Patronato Politico Brasileiro. São Paulo: Globo.

Fernandes, F. (1978). A Integração do Negro na Sociedade de Classes. 3a ed. São Paulo: Ática.

G1. (2018). Capoeirista esfaqueado em Salvador foi morto após dizer que era contra Bolsonaro, diz SSP. Disponible en

https://g1.globo.com/ba/bahia/noticia/2018/10/08/capoeiristaesfaqueado-em-salvador-foi-morto-apos-falar-de-discorda-deopiniao-politica-de-suspeito-do-crime.ghtml (Recuperado 02 marzo 2019).

Isto É. (2018). Para Haddad, Bolsonaro não participa de debate por não ter plano para o País. Disponible en

https://istoe.com.br/para-haddad-bolsonaro-nao-participa-de-debate-pornao-ter-plano-para-o-pais/ (Recuperado 02 marzo 2019).

Luttwak, E. (1991). Golpe de estado: um manual prático. Rio de Janeiro: Paz e Terra.

Menezes, W. (2017). Estado de exceção e democracia fragmentada no Brasil: um breve ensaio a respeito do "golpeachment" de 2016. Revista Lumen, 2. 
Mezarobba, G. (2011). Between Reparations, Half Truths and Impunity: The Difficult Break with the Legacy of the Dictatorship in Brazil*. SUR International Journal on Human Rights. 1. 7-25.

Moisés, J. (2005). A desconfiança nas instituições democráticas. Opinião Pública, Campinas, 11.

O Globo. (2018). OEA não encontra qualquer fraude em urnas, mas destaca agressividade das eleições. Disponible en

https://oglobo.globo.com/brasil/oea-nao-encontra-qualquer-fraude-emurnas-mas-destaca-agressividade-das-eleicoes-23140848 (Recuperado 02 marzo 2019).

Peixinho, M. (2017). O proceso de impeachment no Brasil e o estado democrático de direito. Revista Quaestio Iuris, 10.

Revista Forum. (2018). Eleitores de Bolsonaro postam foto com armas na urna. Disponible en

https://www.revistaforum.com.br/eleitores-de-bolsonaro-postam-fotocom-armas-na-urna-video/ (Recuperado 02 marzo 2019).

Sobrino, L., Moares, F. (2017). Crime ou desconfiança: como caem os governos no presidencialismo brasileiro e no parlamentarismo. Revista de Teorias da Democracia e Direitos Políticos, 3.

Sodré, N. (1997). Era o golpe de 1964 inevitável? In Toledo, C. (org). 1964: visões críticas do golpe: democracia e reformas no populismo. Campinas: Editora da Unicamp. 